\title{
The Interconnection between the Coordinate Distribution of Mueller-Matrixes Images Characteristic Values of Biological Liquid Crystals Net and the Pathological Changes of Human Tissues
}

\author{
Oleg V. Angelsky, Yuriy A. Ushenko, Alexander V. Dubolazov, and Olha Yu. Telenha \\ Correlation Optics Department, Chernivtsi National University, 2 Kotsyubynsky Street, 58012 Chernivtsi, Ukraine \\ Correspondence should be addressed to Oleg V. Angelsky, angelsky@itf.cv.ua
}

Received 1 December 2009; Revised 18 March 2010; Accepted 6 April 2010

Academic Editor: Igor I. Mokhun

Copyright ( 2010 Oleg V. Angelsky et al. This is an open access article distributed under the Creative Commons Attribution License, which permits unrestricted use, distribution, and reproduction in any medium, provided the original work is properly cited.

\begin{abstract}
We have theoretically grounded conceptions of characteristic points observed in coordinate distributions of Mueller matrix elements for a network of human tissue biological crystals. The interrelation between polarization singularities of laser images inherent to these biological crystals and characteristic values of above matrix elements is found. We have determined the criteria for statistical diagnostics of pathological changes in the birefringent structure of biological crystal network by using myometrium tissue as an example.
\end{abstract}

\section{Introduction}

In recent years, in laser diagnostics of biological tissue (BT) structures they effectively use the model approach [1] that allows considering this object as containing two components: amorphous and optically anisotropic ones. Topicality of this modeling is related with the possibility to apply the Mueller matrix analysis of changes in polarization properties caused by transformation of the optic-and-geometric structure of anisotropic components in these biological objects [2-7], optical properties of which are often described using the Mueller matrix [8].

Being based on the approximation of a single light scattering, they found interrelation between the set of statistic distribution moments of the first to fourth orders that characterizes orientation and phase structure of BT birefringent architectonics as well as the set of respective moments [9] for two-dimensional distributions of Mueller matrix elements or Mueller-matrix images (MMIs) [10-14], that is, as it was done during the investigation of random phase objects [15]. In parallel with traditional statistical investigations, formed in the recent 10 to 15 years is the new optical approach to describe a structure of polarization inhomogeneous fields in the case of scattered coherent radiation. The main feature of this approach is the analysis of definite polarization states to determine the whole structure of coordinate distributions for azimuths and ellipticities of polarization. The so-called polarization singularities are commonly used as the following states [15-32].

(i) States with linear polarization when the direction of rotation for the electric field vector is indefinite, the so-called $L$-points.

(ii) Circularly-polarized states when the azimuth of polarization for the electric field vector is indefinite, the so-called $C$-points.

Investigations of polarization inhomogeneous object fields for BT with different morphology [33-35] allowed us to ascertain that they possess a developed network of $L$ - and $C$-points. For example in [34], the authors found interrelations between conditions providing formation of polarization singular points and particularity of the orientation-phase structure of biological crystals present in territorial matrix of human tissue architectonic network. These interrelations served as a base to make statistical and fractal analyses of distribution densities for the number 
of singular points in BT images. As a result, the authors confirmed the efficiency of this method for investigation of object fields to differentiate optical properties of BT with a different morphological structure and physiological state.

The present work is devoted to investigation of new possibilities and differentiation of such objects on the basis of statistic analysis of Mueller matrix characteristic values coordinate distributions, which correspond to polarization singular states in laser image of BT layer.

\section{Characteristic Values of the Mueller-Matrix Images of Biological Tissues}

In accordance with a two-component biological tissue structure its optical properties can be described by combination of Mueller matrixes of isotropic $\{A\}$ and anisotropic $\{F\}$ structures. Each of these components is characterized by intrinsic matrix operators

$$
\{A\}=\left\|\begin{array}{llll}
1 & 0 & 0 & 0 \\
0 & 1 & 0 & 0 \\
0 & 0 & 1 & 0 \\
0 & 0 & 0 & 1
\end{array}\right\| \cdot e^{-\tau l}
$$

where $\tau$ is the extinction coefficient inherent to the layer of biological tissue with the geometric thickness $l$

$$
\{F\}=\left\|\begin{array}{cccc}
1 & 0 & 0 & 0 \\
0 & f_{22} & f_{23} & f_{24} \\
0 & f_{32} & f_{33} & f_{34} \\
0 & f_{42} & f_{43} & f_{44}
\end{array}\right\|=\left\|\begin{array}{cccc}
1 & 0 & 0 & 0 \\
0 & \cos ^{2} 2 \rho+\sin ^{2} 2 \rho \cdot \cos \delta & \cos 2 \rho \sin 2 \rho(1-\cos \delta) & \sin 2 \rho \sin \delta \\
0 & \cos 2 \rho \sin 2 \rho(1-\cos \delta) & \sin ^{2} 2 \rho+\cos ^{2} 2 \rho \cos \delta & \cos 2 \rho \sin \delta \\
0 & -\sin 2 \rho \sin \delta & -\cos 2 \rho \sin \delta & \cos \delta
\end{array}\right\| .
$$

Here, $\rho$ is the orientation of a protein fibril in the architectonic network, the matter of which introduces the phase shift $\delta$ between orthogonal components of the laser wave amplitudes.

The analysis of (1) and (2) shows that the major role in laser beam polarization state transformation belongs to birefringent fibrils network. Among the different values of $\rho$ and $\delta$ one can separate the particular (characteristic) values of orientation $\rho^{*}$ and phase $\delta^{*}$ protein fibrils of BT extracellular matrix

$$
\begin{aligned}
& \rho^{*}=0^{\circ}, \pm 45^{\circ}, 90^{\circ} ; \\
& \delta^{*}=0^{\circ}, \pm 90^{\circ}, 180^{\circ} .
\end{aligned}
$$

As it can be seen from relations (3) the necessary terms for forming polarization singular states of the optically birefringent crystal laser images are $\left(L:\left(\delta^{*}=0^{\circ}, 180^{\circ}\right)\right.$ and $\pm C:\left(\delta^{*}= \pm 90^{\circ}\right)$ points $)$. The values of the fourth Stokes vector parameter, which correspond to above mentioned polarization singular states of the points in laser image are the following:

$$
\begin{gathered}
S_{4}\left(\rho^{*}, \delta^{*}\right)=0 \Longleftrightarrow L \text {-point, } \\
S_{4}\left(\rho^{*}, \delta^{*}\right)=+1,0 \Longleftrightarrow+C \text {-point, } \\
S_{4}\left(\rho^{*}, \delta^{*}\right)=-1,0 \Longleftrightarrow-C \text {-point. }
\end{gathered}
$$

On the other hand, the values (3) for biological crystals network parameters are connected with particular (characteristic) values of Mueller matrix elements $f_{i k}^{*}\left(\rho^{*}, \delta^{*}\right)$.

Considering expressions (2)-(4) the characteristic values $f_{i k}^{*}$ were defined, corresponding to the $L$ - and $C$-points in laser image of the extracellular matrix of the BT layer, as follows: (i) the values $f_{44}=0$ correspond to the complete set of $\pm C$-points;

(ii) the complete set of $L$-points of the laser image is caused by the terms $f_{22}=f_{33}=f_{44}=1$.

Mueller-matrix analysis enables us to perform the sampling of polarization singularities of the laser image, formed by biological crystals with orthogonally oriented $\left(\rho=0^{\circ}-\right.$ $90^{\circ}$ and $\rho= \pm 45^{\circ} \equiv 45^{\circ}-135^{\circ}$ ) optical axes to

(i) "orthogonal" $\pm C$-points

$$
\begin{gathered}
f_{33}=0, \quad f_{34,43}= \pm 1- \pm C_{0 ; 90}-\left(\rho=0^{\circ}-90^{\circ}\right), \\
f_{22}=0, \quad f_{24,42}= \pm 1- \pm C_{45 ; 135}-\left(\rho=45^{\circ}-135^{\circ}\right) ;
\end{gathered}
$$

(ii) “orthogonal" $L_{0 ; 90}$ - and $L_{45 ; 135}$-points

$$
\begin{gathered}
f_{24,42}=0-L_{0 ; 90}-\left(\rho=0^{\circ}-90^{\circ}\right), \\
f_{34,43}=0-L_{45 ; 135}-\left(\rho=45^{\circ}-135^{\circ}\right) .
\end{gathered}
$$

Thus, measuring the coordinate distributions of the characteristic values $\left(f_{i k}^{*}=0, \pm 1\right)$ of the BT Mueller matrix elements enables us not only to foresee the scenario of forming the ensemble of polarization singularities of its image, but also to additionally realize their differentiation, conditioned by the specificity of orientation structure of biological crystals. 


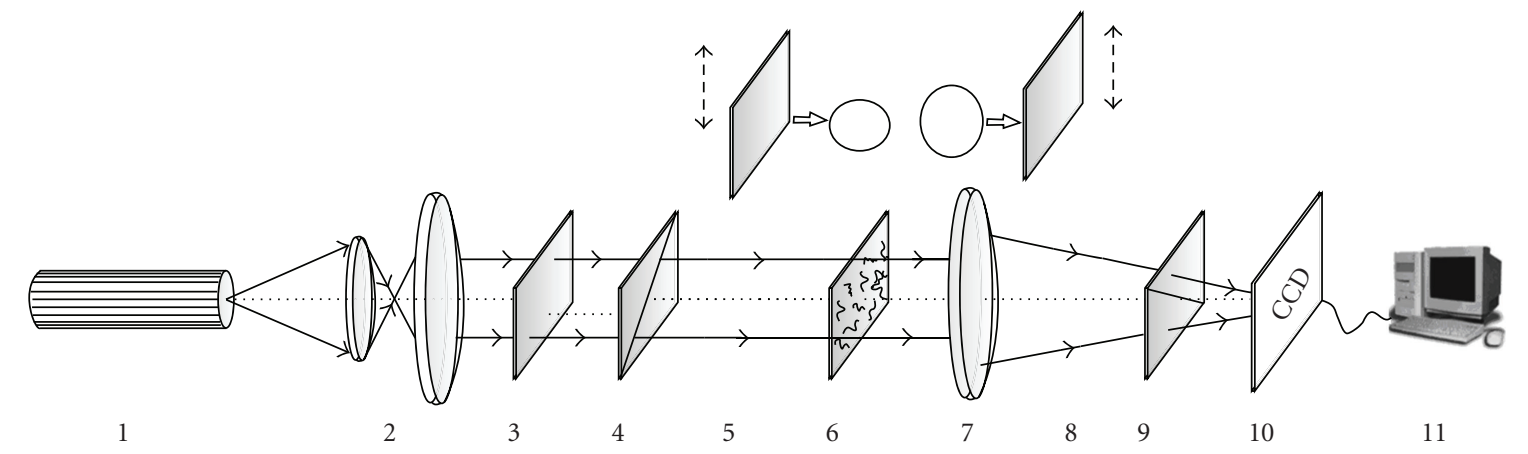

FIGURE 1: Optical scheme of a polarimeter: 1: He-Ne laser; 2: collimator; 3: stationary quarter-wave plate; 5, 8: mechanically movable quarter-wave plates; 4, 9: polarizer and analyzer, respectively; 6: studied object; 7: micro-objective; 10: CCD camera; 11: personal computer.

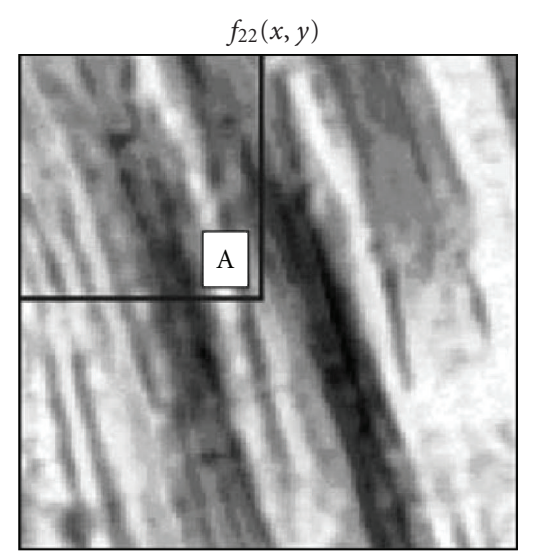

(a)

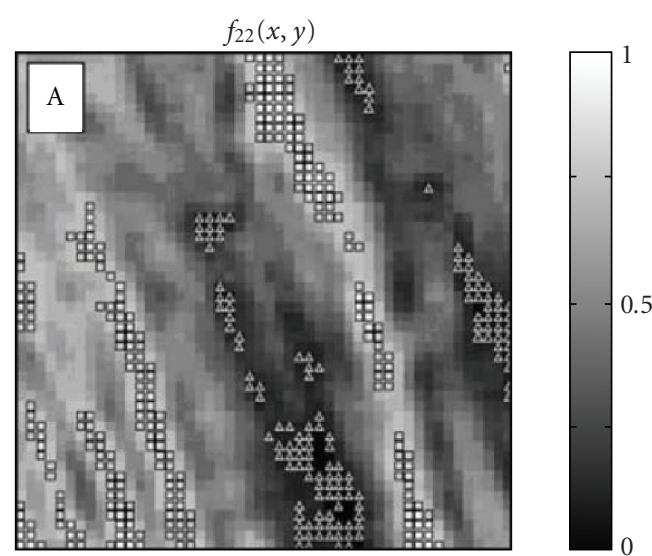

(b)

Figure 2: Coordinate structure of the matrix element $f_{22}$ for myometrium (a). A: coordinate distribution of characteristic values $f_{22}=1,0$ labeled as $(\square)$ and $f_{22}=0$ labeled as $(\triangle)$.

\section{The Scheme of Experimental Measuring the Coordinate Distributions of Characteristic Points in Mueller Matrix Images of Biological Tissues}

Figure 1 shows the traditional optical scheme of a polarimeter to measure the sets of MMI of BT [14].

Illumination was performed with a parallel $(\varnothing=$ $\left.10^{4} \mu \mathrm{m}\right)$ beam of a He-Ne laser $(\lambda=0.6328 \mu \mathrm{m}, W=$ $5.0 \mathrm{~mW}$ ). The polarization illuminator consists of the quarter-wave plates 3 and 5 as well as polarizer 4 , which provides formation of a laser beam with an arbitrary azimuth $0^{\circ} \leq \alpha_{0} \leq 180^{\circ}$ or ellipticity $0^{\circ} \leq \beta_{0} \leq 90^{\circ}$ of polarization.

Polarization images of BT were projected using the micro-objective 7 into the light-sensitive plane $(800 \times 600$ pixels) of CCD-camera 10 that provided measurements of BT structural elements within the range 2 to $2,000 \mu \mathrm{m}$.

Experimental conditions were chosen in such a manner that spatial-angular filtration was practically eliminated when forming BT images. It was provided by matching the angular characteristics of light scattering indicatrices by BT samples $\left(\Omega \approx 16^{\circ}\right)$ and angular aperture of the microobjective $\left(\Delta \omega=20^{\circ}\right)$. Here, $\Omega$ is the angular cone of an indicatrix where $98 \%$ of the total scattered radiation energy is concentrated.

Analysis of BT images was made using the polarizer 9 and quarter-wave plate 8 . As a result, we determined the Stokes vectors for BT images $\left\{S_{j=1,2,3,4}\right\}$ and calculated the ensemble of Mueller matrix elements in one point illuminated with a laser beam in accord with the following algorithm:

$$
\begin{gathered}
f_{i 1}=0.5\left[S_{i}^{(1)}+S_{i}^{(2)}\right], \\
f_{i 2}=0.5\left[S_{i}^{(1)}-S_{i}^{(2)}\right], \\
f_{i 3}=S_{i}^{(3)}-f_{i 1}, \\
f_{i 4}=S_{i}^{(4)}-f_{i 1}, \quad i=1,2,3,4 .
\end{gathered}
$$

The indexes 1 to 4 correspond to the following polarization states of the beam illuminating BT: $1: 0^{\circ} ; 2: 90^{\circ} ; 3:+45^{\circ}$; 4: $\otimes$ (right circulation).

The method used to measure MMI characteristic values for BT samples was as follows.

(i) BT mount was illuminated with a laser beam, within the area of which, in accord with the algorithm (7) we 


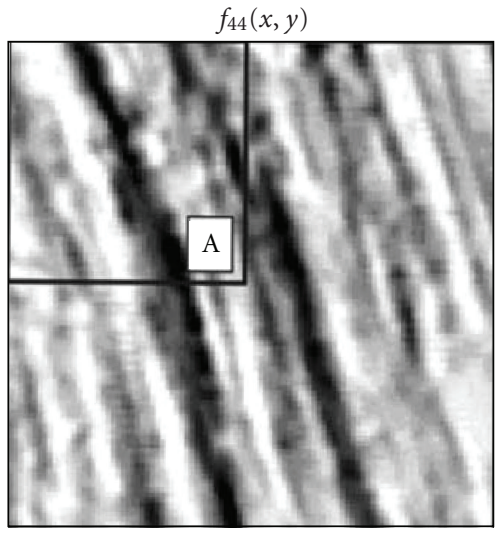

(a)
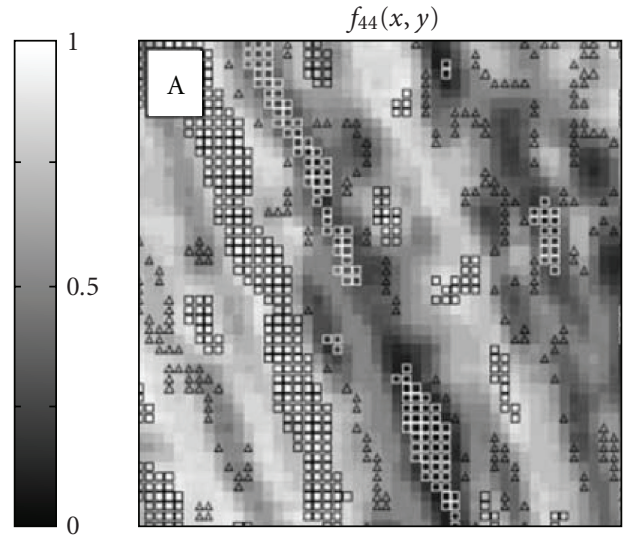

(b)

Figure 3: Coordinate structure of the matrix element $f_{44}$ for myometrium (a). A: coordinate distribution of characteristic values $f_{44}=1,0$ labeled as $(\square)$ and $f_{44}=0$ labeled as $(\triangle)$.

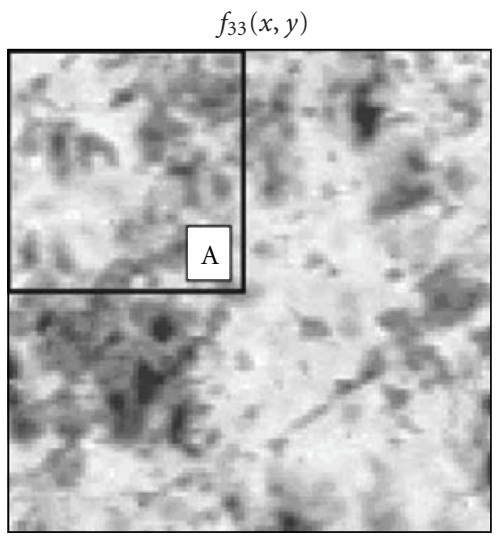

(a)
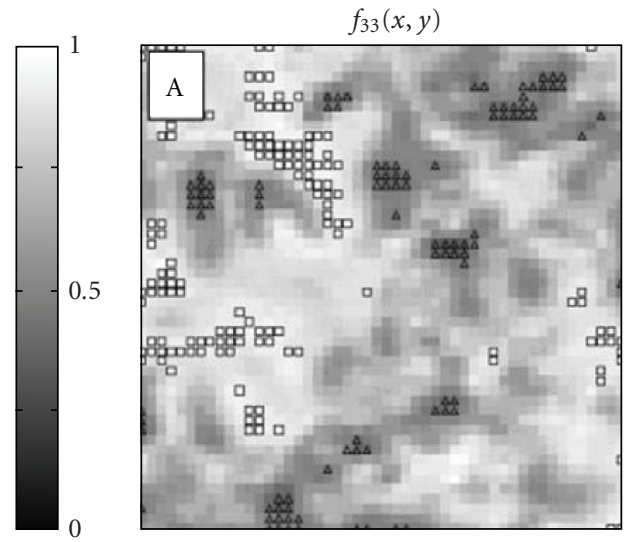

(b)

FIGURE 4: Coordinate structure of the matrix element $f_{33}$ for myometrium (a). A: coordinate distribution of characteristic values $f_{33}=1,0$ labeled as $(\square)$ and $f_{33}=0$ labeled as $(\triangle)$.

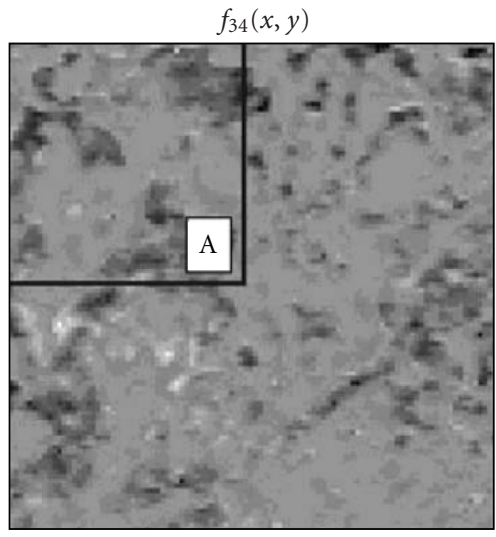

(a)
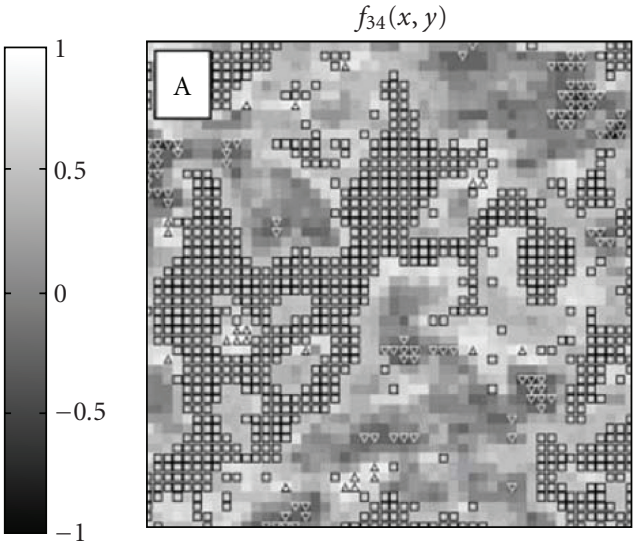

(b)
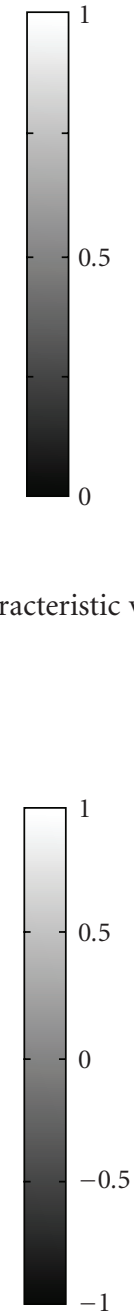

FIgURE 5: Coordinate structure of the matrix element $f_{34}$ for myometrium (a). A: coordinate distribution of characteristic values $f_{34}=0$ labeled as $(\square): f_{34}=+1,0(\triangle)$ and $f_{34}=-1,0(\nabla)$. 


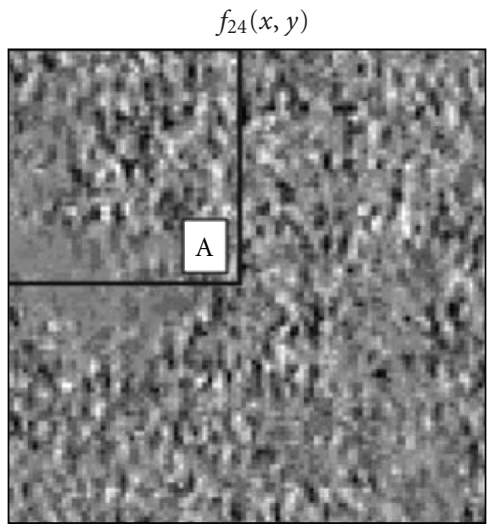

(a)
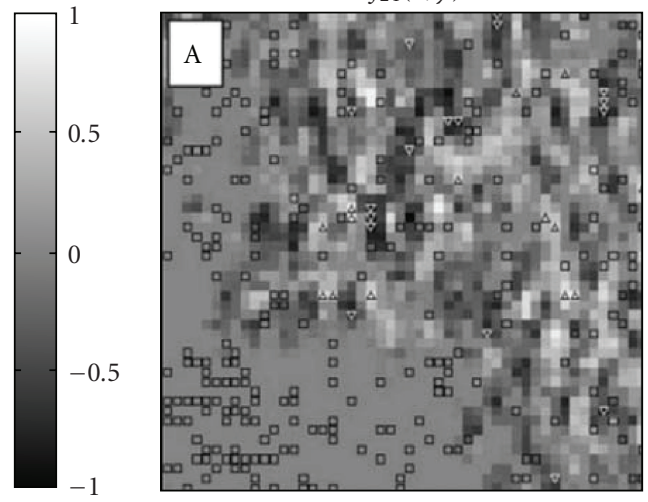

(b)

Figure 6: Coordinate structure of the matrix element $f_{24}$ for myometrium (a). A: coordinate distribution of characteristic values $f_{24}=0$ labeled as $(\square), f_{24}=+1,0(\triangle)$ and $f_{24}=-1,0(\nabla)$.

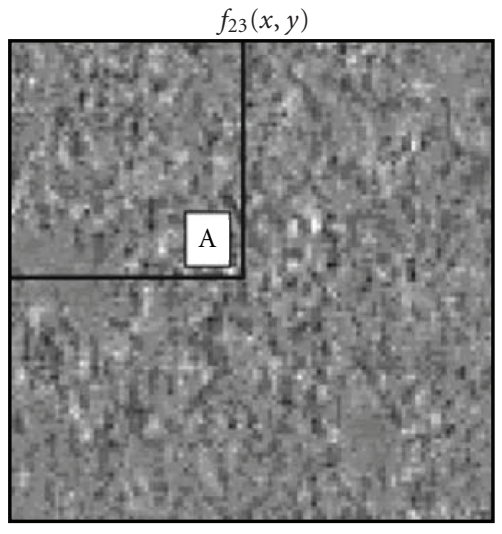

(a)
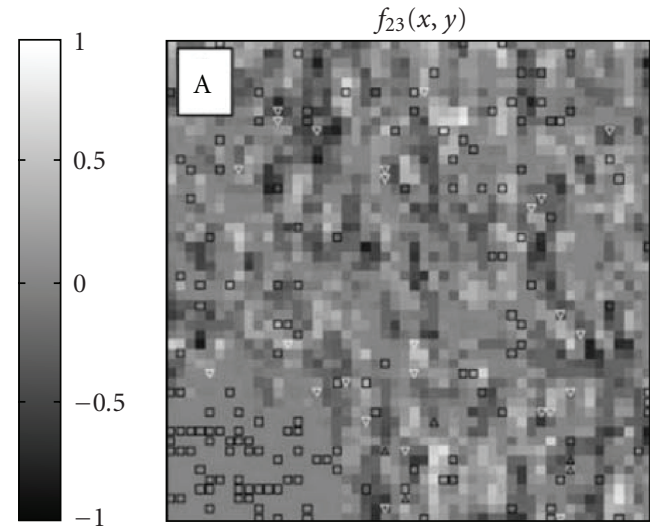

(b)

FIgURE 7: Coordinate structure of the matrix element $f_{23}$ for myometrium (a). A: coordinate distribution of characteristic values $f_{23}=0$ labeled as $(\square), f_{23}=+1,0(\triangle)$ and $f_{23}=-1,0(\nabla)$.

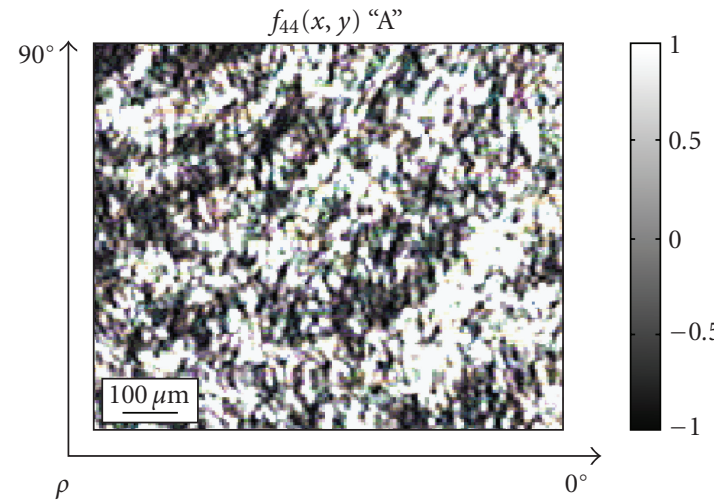

(a)

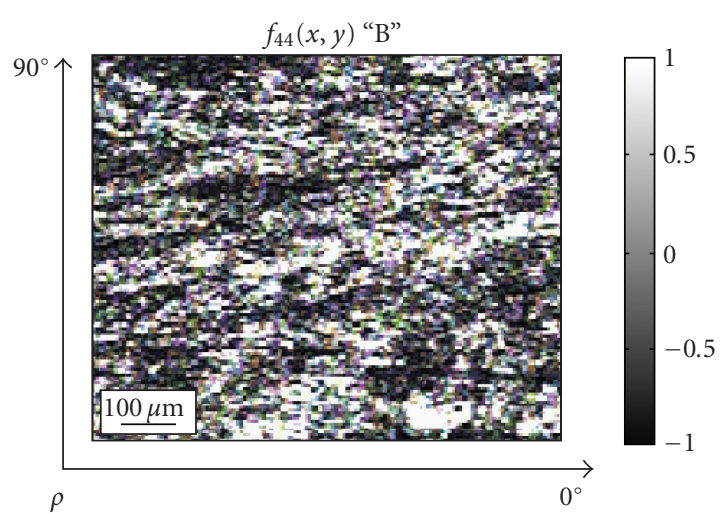

(b)

FIgURE 8: Mueller-matrixes image of the element $f_{44}$ for myometrium tissue of A (a) and B (b) types. 


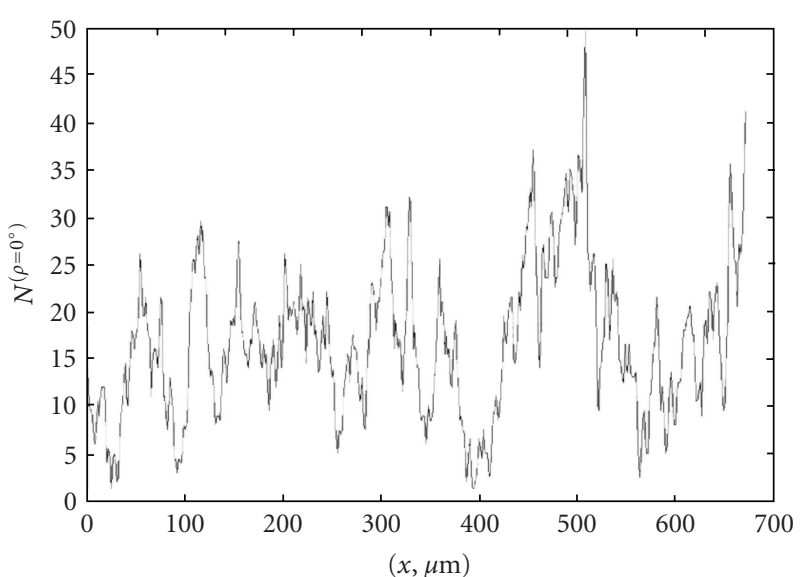

(a)

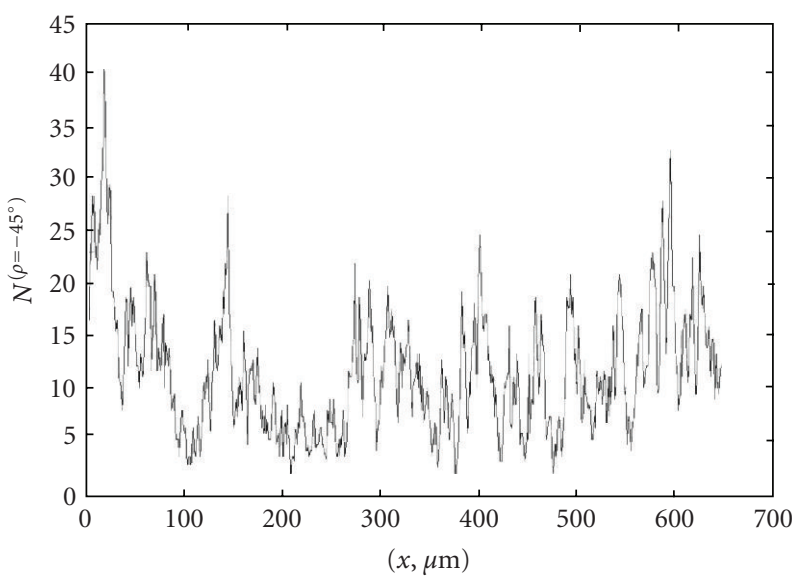

(c)

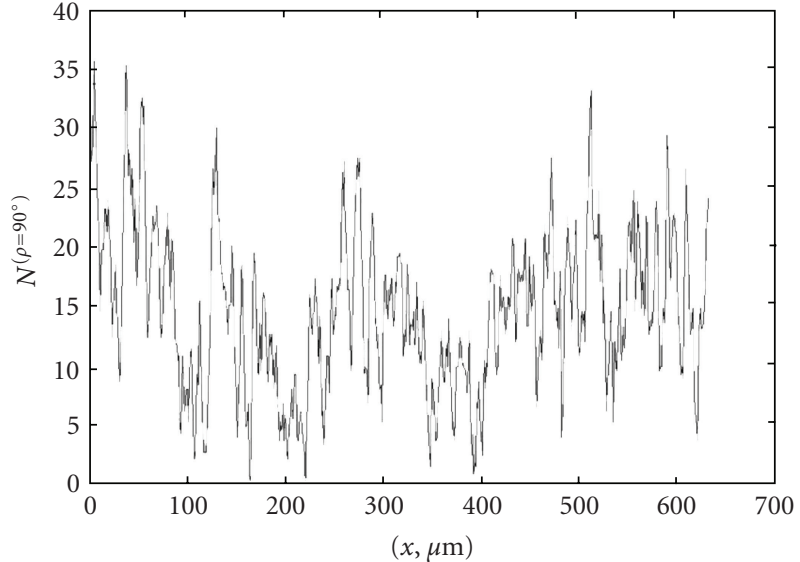

(b)

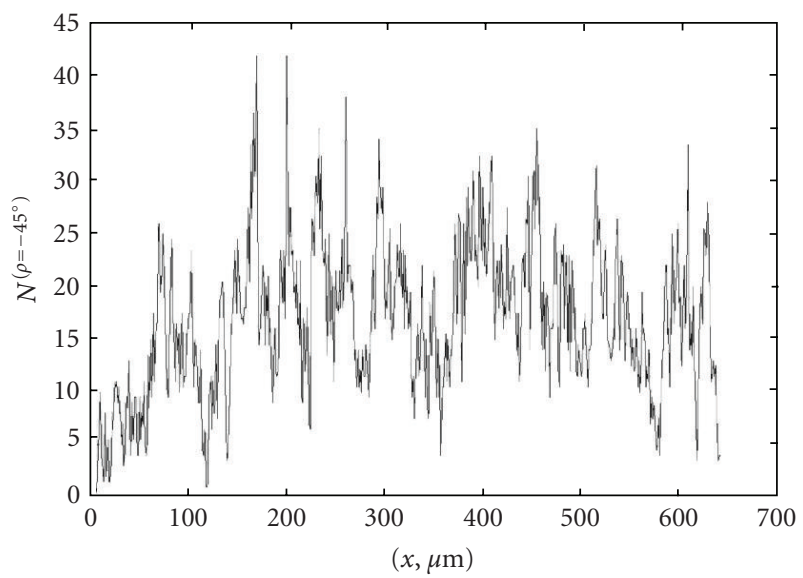

(d)

FIGURE 9: $N_{\rho}(X)$-dependences for myometrium tissue of A type.

determined the array $(m \times n=800 \times 600)$ of values for each element of the Mueller matrix

$$
f_{i k}(m \times n)=\left(\begin{array}{l}
f_{i k}^{11} ; \ldots ; f_{i k}^{1 m} ; \\
f_{i k}^{n 1} ; \ldots ; f_{i k}^{n m}
\end{array}\right) .
$$

(ii) Determined for each massif $f_{i k}(m \times n)$ were coordinate distributions of its characteristic values

$$
f_{i k}^{*}(m \times n)=\left(\begin{array}{l}
f_{i k}^{11}=0 ; \pm 1,0 ; \ldots ; f_{i k}^{1 m}=0 ; \pm 1,0 ; \\
f_{i k}^{n 1}=0 ; \pm 1,0 ; \ldots ; f_{i k}^{n m}=0 ; \pm 1,0 .
\end{array}\right) .
$$

As an object of the experimental study, we used tissues of a woman matrix (myometrium).

\section{Coordinate Distributions of the Mueller Matrixes Images Characteristic Values of Biological Tissues}

Figures 2, 3, 4, 5, 6, and 7 show coordinate distributions for all the types of characteristic values $f_{i k}^{*}$ inherent to the ensemble of protein birefringence liquid crystal net Muellermatrixes images.

As seen from these experimental data, the coordinate distributions of all the Mueller matrix elements for myometrium possess a developed network of characteristic values. Being based on this fact, we have offered Muellermatrixes differentiation of changes in the distribution of optical axis orientations in biological crystals that form the architectonic network, by using as an example the woman matrix tissue.

\section{Mueller-Matrix Diagnostics of Orientation Changes of Liquid Crystals Nets in Biological Tissues}

As objects for our experimental investigations, we used mounts of myometrium tissue of two types:

(i) biopsy of healthy tissue from a woman matrix (type A),

(ii) biopsy of conditionally normal tissue from the vicinity of a benign hysteromyoma (type B). 


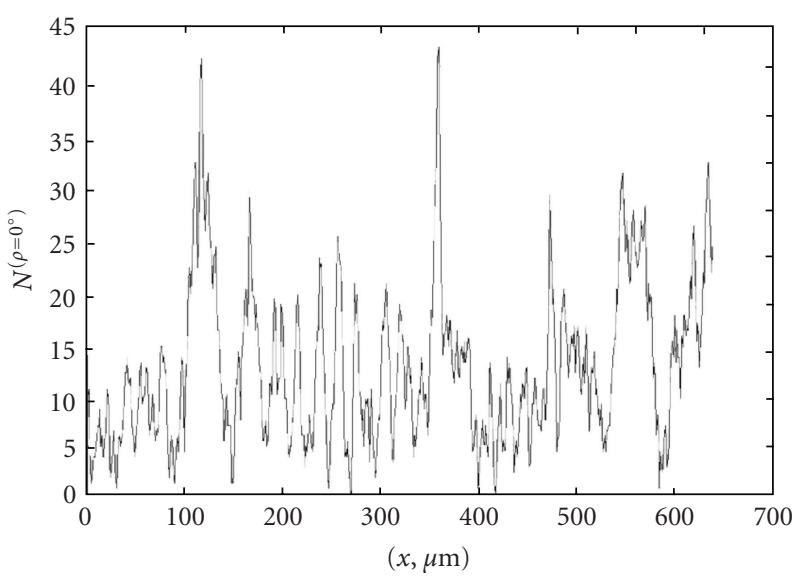

(a)

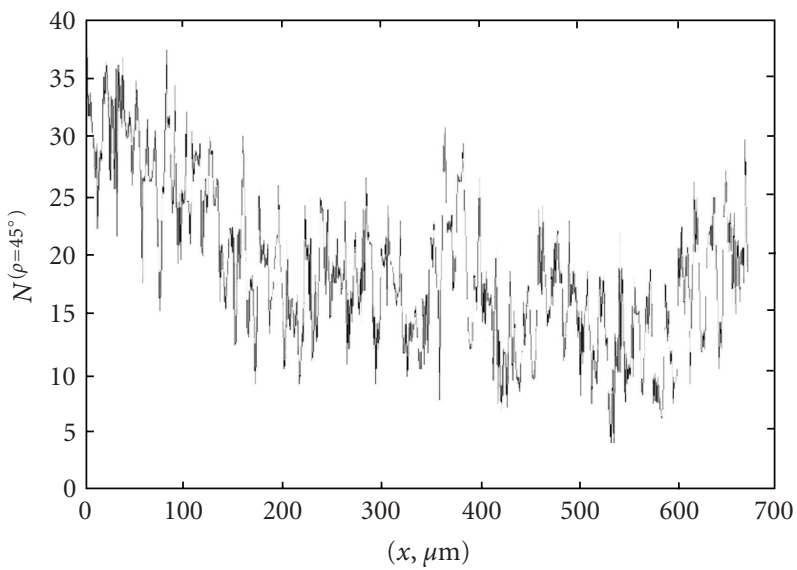

(c)

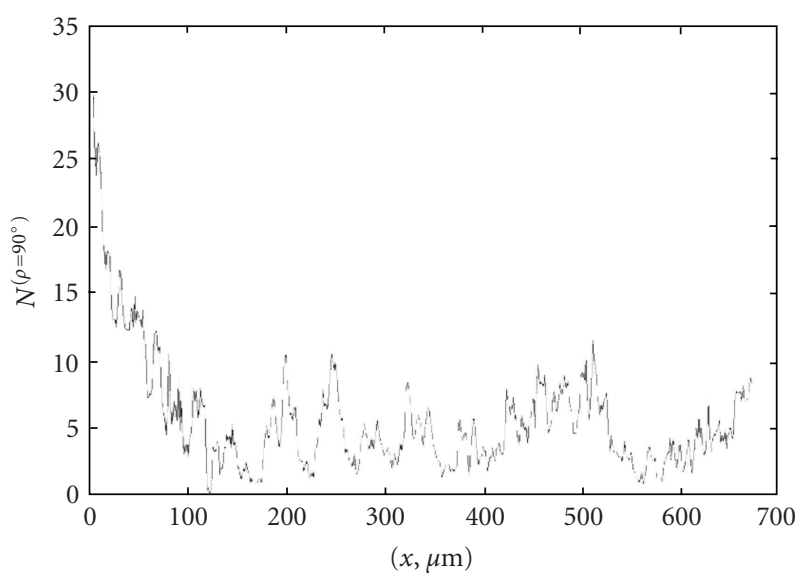

(b)

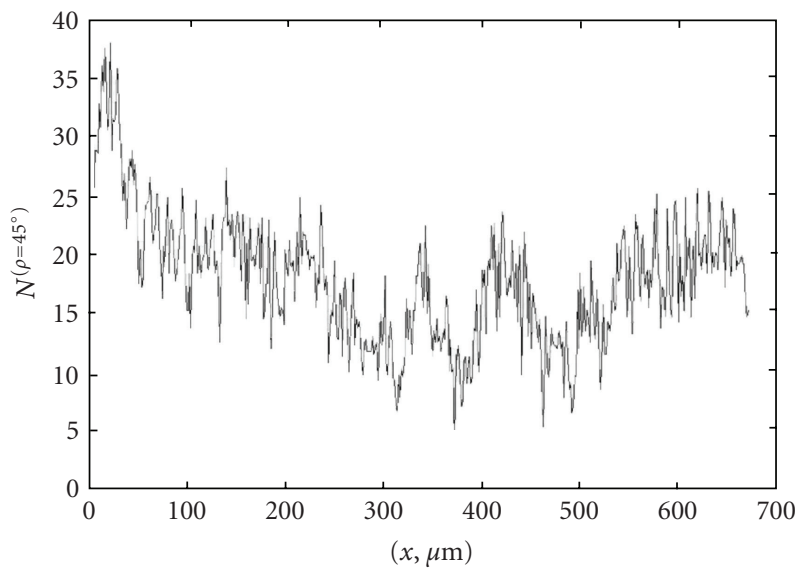

(d)

Figure 10: $N_{\rho}(X)$-dependences for myometrium tissue of B type.

Figure 8 shows MMI of the element $f_{44}$ for myometrium samples of A and B types.

From the optical viewpoint, the obtained two-dimensional distributions $f_{44}(x, y)$ characterize the degree of anisotropy in the matter of studied samples. Thereof, it can be easily seen that the birefringence value of the samples A and $\mathrm{B}$ is practically identical. It is confirmed by the close level of relative values for the matrix element $f_{44}(x, y)$ describing the tissues of $\mathrm{A}$ and B types $\left(f_{44}^{\mathrm{B}}(x, y) \approx f_{44}^{\mathrm{A}}(x, y)\right)$. In parallel with it, one can observe the ordering of the directions of optical axes inherent to anisotropic structures of type B myometrium.

Thus, the main parameter allowing differentiation of optical properties for the samples of this type is the orientation structure of their birefringent networks.

To obtain objective criteria for Mueller-matrix differentiation of optical properties inherent to the myometrium samples of A and B types, we have used the following approach:

(i) measured in sequence were the MMI elements $f_{24,42}$ and $f_{34,43}$, that are basic to determine characteristic states $( \pm 1)$ formed in biological crystals with orthogonal orientations of optical axes $\left(\rho=0^{\circ}\right.$, $90^{\circ} \rightarrow f_{34,43}= \pm 1,0 ; \rho=45^{\circ}, 135^{\circ} \rightarrow f_{24,42}= \pm 1,0$ ((5) and (6));

(a) two-dimension array $x=1 \div m ; y=1 \div n$ of CCD-camera pixels can be represented by the set of columns shifted along the $x$-direction by $\Delta x=1$ pix

$$
\begin{aligned}
m \times n= & \left(\begin{array}{c}
r_{11} \\
\cdot \\
\cdot \\
r_{1 n}
\end{array}\right) \equiv X_{1}, \quad\left(\begin{array}{c}
r_{11}+\Delta x \equiv r_{21} \\
\cdot \\
\cdot \\
r_{1 n}+\Delta x \equiv r_{2 n}
\end{array}\right) \equiv X_{2} ; \ldots, \\
& \left(\begin{array}{c}
r_{11}+(m-1) \Delta x \equiv r_{(m-1) 1} \\
\cdot \\
\cdot \\
r_{11}+(m-1) \Delta x \equiv r_{(m-1) 1}
\end{array}\right) \equiv X_{m-1}, \\
& \left(\begin{array}{c}
r_{11}+m \Delta x \equiv r_{m 1} \\
\cdot \\
\cdot \\
r_{11}+m \Delta x \equiv r_{m 1}
\end{array}\right) \equiv X_{m},
\end{aligned}
$$


(ii) the amount $N_{j=1 \div m}$ of characteristic points $f_{34,43}(x, y)= \pm 1,0$ within each column $X_{j=1 \div m}$ was calculated, and $f_{24,42}(x, y)= \pm 1,0$ within Mueller matrix images obtaining the distributions of
$N_{\rho}(X)$ for different optical axes orientations $\rho=0^{\circ}$; $90^{\circ},+45^{\circ} ; 135^{\circ}$ of biological crystals birefringent network.

$$
\begin{gathered}
N_{\rho=0}(X)=N_{1}\left(f_{34 ; 43}=+1,0\right) ; N_{2}\left(f_{34 ; 43}=+1,0\right) ; \ldots ; N_{m-1}\left(f_{34 ; 43}=+1,0\right) ; N_{m}\left(f_{34 ; 43}=+1,0\right), \\
N_{\rho=90}(X)=N_{1}\left(f_{34 ; 43}=-1,0\right) ; N_{2}\left(f_{34 ; 43}=-1,0\right) ; \ldots ; N_{m-1}\left(f_{34 ; 43}=-1,0\right) ; N_{m}\left(f_{34 ; 43}=-1,0\right), \\
N_{\rho=45}(X)=N_{1}\left(f_{24 ; 42}=+1,0\right) ; N_{2}\left(f_{24 ; 42}=+1,0\right) ; \ldots ; N_{m-1}\left(f_{24 ; 42}=+1,0\right) ; N_{m}\left(f_{24 ; 42}=+1,0\right), \\
N_{\rho=135}(X)=N_{1}\left(f_{24 ; 42}=-1,0\right) ; N_{2}\left(f_{24 ; 42}=-1,0\right) ; \ldots ; N_{m-1}\left(f_{24 ; 42}=-1,0\right) ; N_{m}\left(f_{24 ; 42}=-1,0\right) .
\end{gathered}
$$

TABLE 1: The skewness coefficients of characteristic values distributions in Mueller-matrix images.

\begin{tabular}{lcc}
\hline$Z$ & $\begin{array}{c}\text { Myometrium } \\
\text { (normal state) } \\
(25 \text { samples) }\end{array}$ & $\begin{array}{c}\text { Myometrium } \\
\text { (pathological state) } \\
\text { (23 samples) }\end{array}$ \\
\hline$Q_{M}^{f_{43,34}}$ & $0.03 \pm 0.005$ & $0.45 \pm 0.063$ \\
$W_{\sigma}^{f_{43,34}}$ & $0.02 \pm 0.004$ & $0.12 \pm 0.019$ \\
$Q_{M}^{f_{42,24}}$ & $0.025 \pm 0.0036$ & $0.28 \pm 0.037$ \\
$W_{\sigma}^{f_{42,24}}$ & $0.03 \pm 0.0047$ & $0.14 \pm 0.021$ \\
\hline
\end{tabular}

(iii) $N_{\rho}(X)$ dependences were processed using the following algorithms

$$
\begin{gathered}
Q_{M}^{\left(f_{34,43}\right)}=\frac{M\left(N_{\rho=0^{\circ}}\right)-M\left(N_{\rho=90^{\circ}}\right)}{M\left(N_{\rho=0^{\circ}}\right)+M\left(N_{\rho=90^{\circ}}\right)}, \\
Q_{M}^{\left(f_{24,42}\right)}=\frac{M\left(N_{\rho=45^{\circ}}\right)-M\left(N_{\rho=135^{\circ}}\right)}{M\left(N_{\rho=45^{\circ}}\right)+M\left(N_{\rho=135^{\circ}}\right)} . \\
W_{\sigma}^{\left(f_{34,43}\right)}=\frac{\sigma\left(N_{\rho=0^{\circ}}\right)-\sigma\left(N_{\rho=90^{\circ}}\right)}{\sigma\left(N_{\rho=0^{\circ}}\right)+\sigma\left(N_{\rho=90^{\circ}}\right)}, \\
W_{\sigma}^{\left(f_{24,42}\right)}=\frac{\sigma\left(N_{\rho=45^{\circ}}\right)-\sigma\left(N_{\rho=135^{\circ}}\right)}{\sigma\left(N_{\rho=45^{\circ}}\right)+\sigma\left(N_{\rho=135^{\circ}}\right)} .
\end{gathered}
$$

Here, $M\left(N_{\rho}\right)$ and $\sigma\left(N_{\rho}\right)$ are the average and dispersion of $N_{\rho}(X)$ distributions.

Shown in Figures 9 and 10 are the distributions $N_{\rho}(X)$ of Mueller-matrixes images for the myometrium tissue of $A$ and B types.

In the case of myometrium tissue with pathological changes, one can observe asymmetry between the ranges of changes in values of the dependences $N_{\rho=0}(X)$ (Figure 10(a)) and $N_{\rho=90}(X)$ (Figure 10(b)).

The above results can be explained as based on the relation found between conditions, providing formation of MMI characteristic values and orientation-phase structure of biological crystals in the myometrium tissue ((5) and (6)).
Orientation structure of MMI for the element $f_{44}$ describing the myometrium tissue of B type (Figure 8(b)) contains characteristic points $f_{44}(x, y)=1,0$ asymmetrically located in the direction $\rho=90^{\circ}$. Thereof, one should expect a maximal number of characteristic values for the element $f_{34}(x, y)=-1,0$ as compared to that of characteristic values $f_{34,43}(x, y)=1,0$ and $f_{24,42}(x, y)= \pm 1,0$.

Statistically found asymmetry in distributions of characteristic points for MMI describing the myometrium tissue of both types was estimated using the asymmetry coefficients (12) introduced by us. Table 1 shows statistically averaged values of the coefficients $Q_{M}$ and $W_{\sigma}$ within two groups of myometrium samples of A and B types.

Analysis of data represented in Table 1 allowed us to conclude the following:

(i) first- and second-order statistical moments for distributions of characteristic values $f_{34,43}(x, y)$ and $f_{24,42}(x, y)$ of healthy myometrium tissue do not practically differ from zero, which is indicative of their azimuthal symmetry;

(ii) values of the skewness coefficient for distributions of MMI characteristic values $f_{34,43}(x, y)$ and $f_{24,42}(x, y)$ describing the pathologically changed myometrium tissue of B type grow practically by one order, which indicates the formation of their azimuthal asymmetry related with the direction of pathological growth of birefringent protein fibrils.

\section{Conclusion}

Thus, the above analysis of statistical distributions describing the number of points for MMI characteristic values inherent to the set of elements $f_{i k}$ characterizing biological tissues of different kinds seems to be efficient in differentiation of phase and orientation changes in the structure of their birefringent components, which are related with changes in their physiological state. 


\section{References}

[1] S. C. Cowin, "How is a tissue built?" Journal of Biomechanical Engineering, vol. 122, no. 6, pp. 553-569, 2000.

[2] O. V. Angelsky, A. G. Ushenko, Yu. A. Ushenko, Ye. G. Ushenko, Yu. Ya. Tomka, and V. P. Pishak, "Polarizationcorrelation mapping of biological tissue coherent images," Journal of Biomedical Optics, vol. 10, no. 6, Article ID 064025, 2005.

[3] J. F. de Boer and T. E. Milner, "Review of polarization sensitive optical coherence tomography and Stokes vector determination," Journal of Biomedical Optics, vol. 7, no. 3, pp. 359-371, 2002.

[4] J. F. de Boer, T. E. Milner, and J. S. Nelson, "Two dimensional birefringence imaging in biological tissue using phase and polarization sensitive optical coherence tomography," in Trends in Optics and Photonics (TOPS): Advances in Optical Imaging and Photon Migration, OSA, Washington, DC, USA, 1998.

[5] M. J. Everett, K. Schoenenberger, B. W. Colston Jr., and L. B. Da Silva, "Birefringence characterization of biological tissue by use of optical coherence tomography," Optics Letters, vol. 23, no. 3, pp. 228-230, 1998.

[6] O. V. Angelsky, G. V. Demianovsky, A. G. Ushenko, D. N. Burkovets, and Y. A. Ushenko, "Wavelet analysis of two-dimensional birefringence images of architectonics in biotissues for diagnosing pathological changes," Journal of Biomedical Optics, vol. 9, no. 4, pp. 679-690, 2004.

[7] O. V. Angelsky, Yu. Ya. Tomka, A. G. Ushenko, Ye. G. Ushenko, S. B. Yermolenko, and Yu. A. Ushenko, "2-D tomography of biotissues images in pre-clinic diagnostics of their pre-cancer states," in Advanced Topics in Optoelectronics, Microelectronics, and Nanotechnologies II, vol. 5972 of Proceeding of SPIE, August 2005.

[8] O. V. Angelsky, A. G. Ushenko, D. N. Burkovets, and Yu. A. Ushenko, "Polarization visualization and selection of biotissue image two-layer scattering medium," Journal of Biomedical Optics, vol. 10, no. 1, 2005.

[9] O. V. Angelsky, Yu. Ya. Tomka, A. G. Ushenko, Ye. G. Ushenko, and Yu. A. Ushenko, "Investigation of 2D Mueller matrix structure of biological tissues for pre-clinical diagnostics of their pathological states," Journal of Physics D, vol. 38, no. 23, pp. 4227-4235, 2005.

[10] S. Jiao, W. Yu, G. Stoica, and L. V. Wang, "Optical-fiber-based Mueller optical coherence tomography," Optics Letters, vol. 28, no. 14, pp. 1206-1208, 2003.

[11] Yu. A. Ushenko, "Statistical structure of polarizationinhomogeneous images of biotissues with different morphological structures," Ukrainian Journal of Physical Optics, vol. 6, pp. 63-70, 2005.

[12] O. V. Angelsky, A. G. Ushenko, Yu. A. Ushenko, Ye. G. Ushenko, Yu. Ya. Tomka, and V. P. Pishak, "Polarizationcorrelation mapping of biological tissue coherent images," Journal of Biomedical Optics, vol. 10, no. 6, Article ID 064025, 2005.

[13] O. V. Angelsky, A. G. Ushenko, and Yu. A. Ushenko, "Polarization reconstruction of orientation structure of biological tissues birefringent architectonic nets by using their Muellermatrix speckle-images," Journal of Holography and Speckle, vol. 2, pp. 72-79, 2005.

[14] A. G. Ushenko and V. P. Pishak, "Laser polarimetry of biological tissue. Principles and applications," in Coherent-Domain
Optical Methods. Biomedical Diagnostics, Environmental and Material Science, V. Tuchin, Ed., pp. 67-93, Kluwer Academic Publishers, Dodrecht, The Netherlands, 2004.

[15] O. V. Angelsky and P. P. Maksimyak, "Optical diagnostics of random phase objects,” Applied Optics, vol. 29, pp. 2894-2898, 1990.

[16] O. V. Angelsky, P. P. Maksimyak, V. V. Ryukhtin, and S. G. Hanson, "New feasibilities for characterizing rough surfaces by optical-correlation techniques," Applied Optics, vol. 40, no. 31, pp. 5693-5707, 2001.

[17] J. F. Nye, "Polarization effects in the diffraction of electromagnetic waves: the role of disclinations," Proceedings of the Royal Society A, vol. 387, no. 1792, pp. 105-132, 1983.

[18] O. V. Angelsky, I. I. Mokhun, A. I. Mokhun, and M. S. Soskin, "Interferometric methods in diagnostics of polarization singularities," Physical Review E, vol. 65, no. 3, Article ID 036602, 2002.

[19] J. F. Nye and J. V. Hajnal, "The wave structure of monochromatic electromagnetic radiation," Proceedings of the Royal Society A, vol. 409, no. 1836, pp. 21-36, 1987.

[20] M. V. Berry and M. R. Dennis, "Polarization singularities in isotropic random vector waves," Proceedings of the Royal Society A, vol. 457, no. 2005, pp. 141-155, 2001.

[21] A. D. Dolgov, A. G. Doroshkevich, D. I. Novikov, and I. D. Novikov, "Classification of singular points in the polarization field of the cosmic microwave background and eigenvectors of the Stokes matrix," JETP Letters, vol. 69, no. 6, pp. 427-433, 1999.

[22] A. I. Konukhov and L. A. Melnikov, "Optical vortices in a vector field: the general definition based on the analogy with topological solitons in a 2D ferromagnet, and examples from the polarization transverse patterns in a laser," Journal of Optics B, vol. 3, no. 2, pp. 139-144, 2001.

[23] I. Freund, "Poincare vortices," Optics Letters, vol. 26, no. 24, pp. 1996-1998, 2001.

[24] J. F. Nye, "Lines of circular polarization in electromagnetic wave fields," Proceedings of the Royal Society A, vol. 389, no. 1797, pp. 279-290, 1983.

[25] I. Freund, "Coherency matrix description of optical polarization singularities," Journal of Optics A, vol. 6, no. 5, pp. 229234, 2004.

[26] M. Soskin, V. Denisenko, and R. Egorov, "Topological networks of paraxial ellipse speckle-fields," Journal of Optics A, vol. 6, no. 5, pp. 281-287, 2004.

[27] I. Freund, M. S. Soskin, and A. I. Mokhun, "Elliptic critical points in paraxial optical fields," Optics Communications, vol. 208, no. 4-6, pp. 223-253, 2002.

[28] M. S. Soskin, V. Denisenko, and I. Freund, "Optical polarization singularities and elliptic stationary points," Optics Letters, vol. 28, no. 16, pp. 1475-1477, 2003.

[29] M. R. Dennis, "Polarization singularities in paraxial vector fields: morphology and statistics," Optics Communications, vol. 213, no. 4-6, pp. 201-221, 2002.

[30] O. Angelsky, R. Besaha, A. Mokhun, et al., "Singularities in vectoral fields," in Fourth International Conference on Correlation Optics, O. V. Angelsky, Ed., vol. 3904 of Proceeding of SPIE, Chernivtsy, Ukraine, May 1999.

[31] I. Freund, A. I. Mokhun, M. S. Soskin, O. V. Angelsky, and I. I. Mokhun, "Stokes singularity relations," Optics Letters, vol. 27, no. 7, pp. 545-547, 2002.

[32] O. Angelsky, A. Mokhun, I. Mokhun, and M. Soskin, "The relationship between topological characteristics of component 
vortices and polarization singularities," Optics Communications, vol. 207, no. 1-6, pp. 57-65, 2002.

[33] O. V. Angelsky, A. G. Ushenko, and Ye. G. Ushenko, "2-D Stokes polarimetry of biospeckle tissues images in pre-clinic diagnostics of their pre-cancer states," Journal of Holography and Speckle, vol. 2, pp. 26-33, 2005.

[34] O. V. Angelsky, A. G. Ushenko, Yu. A. Ushenko, and Ye. G. Ushenko, "Polarization singularities of the object field of skin surface," Journal of Physics D, vol. 39, no. 16, pp. 3547-3558, 2006.

[35] O. V. Angelsky, A. G. Ushenko, Ye. G. Ushenko, and Y. Y. Tomka, "Polarization singularities of biological tissues images," Journal of Biomedical Optics, vol. 11, no. 5, Article ID 054030, 2006. 

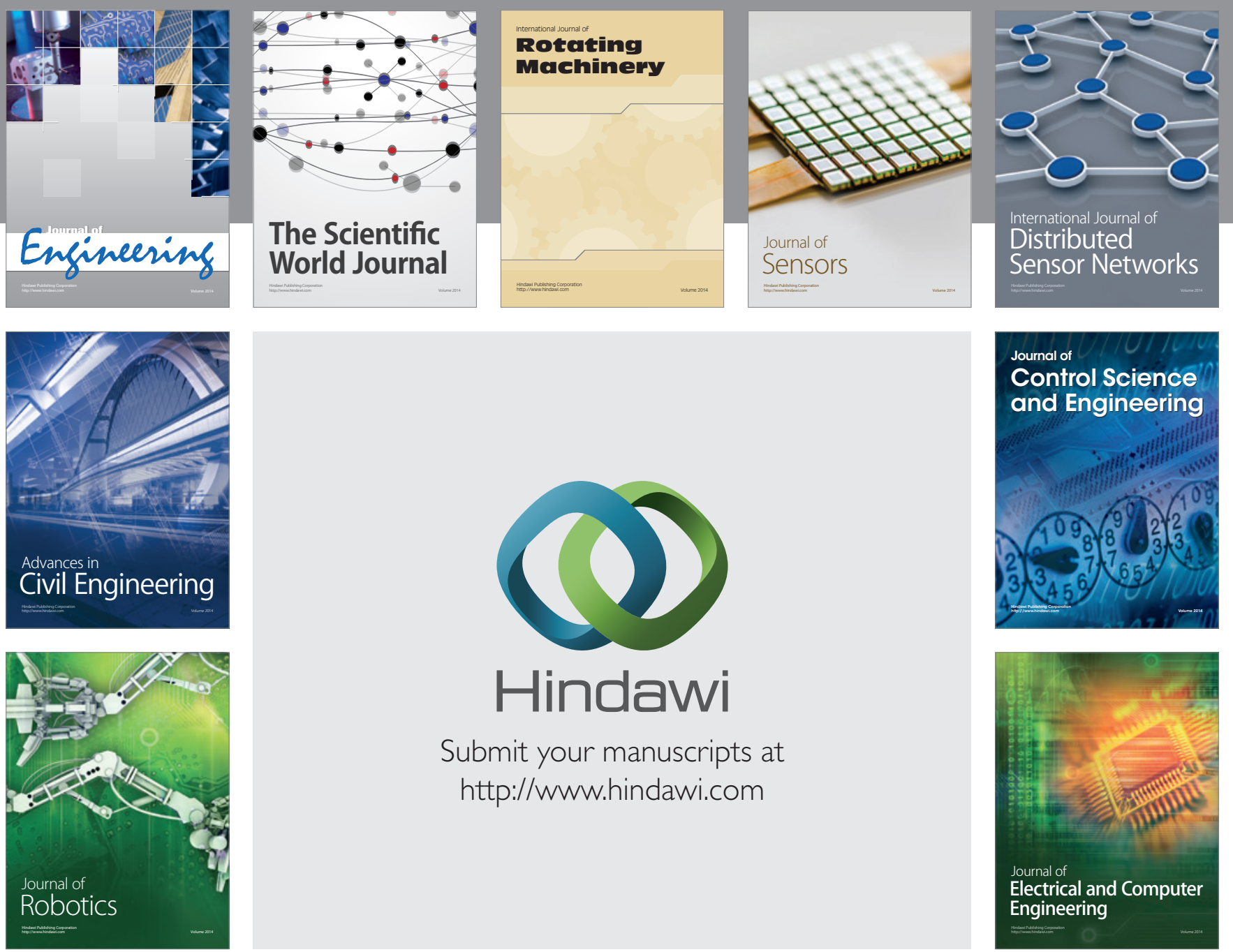

Submit your manuscripts at

http://www.hindawi.com
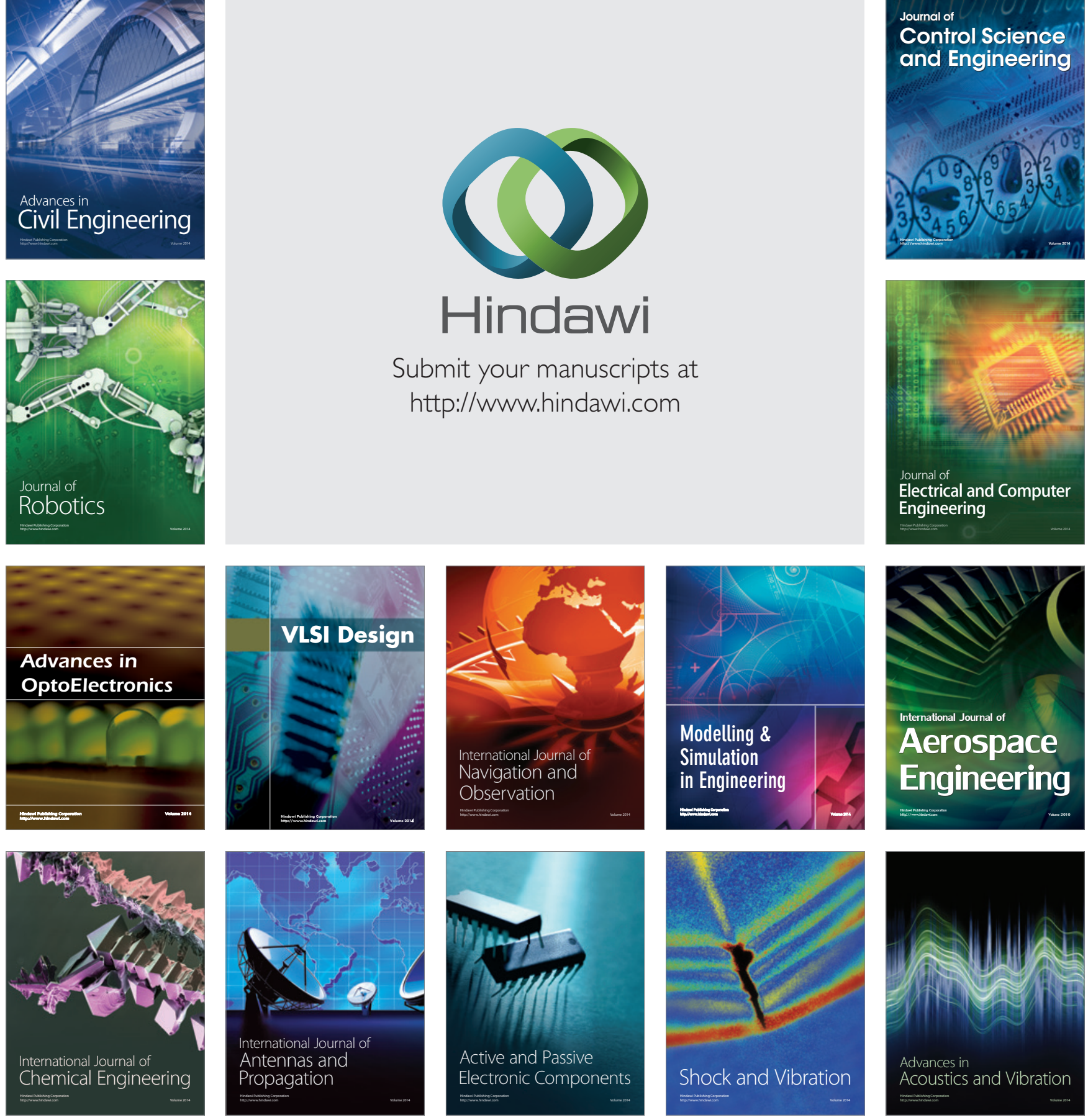